\title{
Can Cutting-Needle Biopsy Be an Alternative to Excisional Biopsy in Lymph Node Pathologies?
}

\author{
Aydan KILIÇARSLAN ${ }^{1}$, Mehmet DOĞAN², Nuran SÜNGÜ1 ${ }^{1}$, Emre KARAKÖK³ ${ }^{3}$ Leman KARABEKMEZ ${ }^{4}$, \\ Mesut AKYOL ${ }^{5}$, Hayriye TATLI DOĞAN'
}

Department of Pathology ' University of Ankara YIIdırım Beyazı School of Medicine, ANKARA, TURKEY, ${ }^{2}$ Dr. Abdurrahman Yurtaslan Oncology Education and Research Hospital, ANKARA, TURKEY, ${ }^{3}$ Atatürk Education and Research Hospital, ANKARA, TURKEY,

Department of ${ }^{4}$ Radiology and ${ }^{5}$ Biostatistics, University of Ankara YIldırım Beyazıt, School of Medicine, ANKARA, TURKEY

\begin{abstract}
Objective: We aimed to compare cutting-needle biopsy (CNB) diagnoses with excisional biopsy diagnoses of enlarging lymph nodes and to determine the diagnostic value of CNB.

Material and Method: Out of the 291 cases that underwent CNB from lymph nodes between 2010 and 2016, 60 were included in the study in which pathological lymph nodes were excised after CNB. Demographic information, pathology and imaging reports, the diameters of the lymph nodes and the length of the CNBs of these cases were obtained from the hospital registry system. Diagnoses of the CNBs and excisional biopsies were then compared.
\end{abstract}

Results: According to the excisional biopsy diagnosis, 7 of the 60 cases (11.7\%) were benign and 53 of them (88.3\%) were malignant. 28 (53\%) of the malignant cases were diagnosed as Hodgkin's lymphoma while the others (47\%) got a non-Hodgkin's lymphoma diagnosis.

In the 8 non-diagnostic CNBs, 3(37\%) of them were found to be benign/reactive, while $5(63 \%)$ were diagnosed as malign lymphoma in excisional biopsy. Similarly, 7(64\%) of the 11 cases diagnosed as benign/reactive in CNB, were found to be malignant with excisional biopsy. When CNB and excisional biopsy were compared, sensitivity and specificity were $90 \%$ and $100 \%$; positive predictive value (PPV) and negative predictive value (NPV) were $100 \%$ and $0 \%$, respectively, and the diagnostic accuracy rate (DV) was $86.5 \%$. The mean diameter of the benign lymph nodes was $26.1 \mathrm{~mm}$ and the mean diameter of the malignant ones was $35.6 \mathrm{~mm}$. There was no significant difference between malignant and benign lymph node size ( $\mathrm{p}>0.05$ ). There was also no statistically significant difference between CNB length and correct diagnosis ( $\mathrm{p}=0.233$ ).

Conclusion: CNB is a non-invasive procedure. It is an alternative to excisional biopsy because of its low morbidity and low cost. However, the sensitivity of CNB is lower than its specificity, and we recommend the surgical excision of lymph nodes with a clinically strong neoplasm suspicion because of the presence of false negatives in 7 cases.

Key Words: Lymphoma, Needle biopsy, Lymph nodes

\section{INTRODUCTION}

Malignant lymphomas (i. e., both Hodgkin and nonHodgkin lymphomas) are often associated with lymph nodes that are enlarging in the neck region and tissue samples are needed for diagnosis. Today, a diagnosis of malignant lymphoma is insufficient for oncologic therapy unless it is subclassified (1). Excisional biopsy of the lymph node is accepted as the gold standard in exact diagnosis of these neoplasms (2-5). In some cases, in order to perform excisional or incisional biopsies, the patient needs to be hosted in a hospital and operating room conditions. In addition, complications such as temporary or permanent seroma at the site of incision, necrosis at flap border, wound infection, scarring, nerve injury, thrombophlebitis and bleeding may occur $(6,7)$. Image (CT or ultrasound)-guided

(Turk Patoloji Derg 2017, 33:235-239)

Received : 03.01.2017 Accepted : 26.01.2017 cutting-needle biopsy (CNB) is a less invasive method and an alternative to excisional biopsy (4). CNB is a generally cheap, feasible, fast, simple and well tolerable method. Many centers prefer tissue sampling with CNB. In recent years, the role of percutaneous biopsies of lymphoproliferative diseases is gaining importance with advances in biopsy, histopathology and immunohistochemistry techniques $(4,8-10)$. CNB allows not only to simply differentiate the lymphoproliferative diseases as malignant or benign, but also allows for the definitive diagnosis of Hodgkin's lymphoma (HL) and non-Hodgkin's lymphoma (NHL) subtypes $(11,12)$.

Our aim in this study was to compare the diagnoses obtained by $\mathrm{CNB}$ and excisional biopsy and to demonstrate the diagnostic value of CNB.
Correspondence: Aydan KILIÇARSLAN

University of Ankara Yıldırım Beyazıt, School of Medicine,

Department of Pathology, ANKARA, TURKEY

E-mail: dr.kilicaydan@gmail.com Phone: +90 3122912743 


\section{MATERIALS and METHODS}

Two hundred and ninety-one cases that underwent ultrasound-guided CNB between 2010 and 2016 were evaluated retrospectively. Among these, 60 patients who underwent lymph node excision for diagnostic purposes after a CNB with a minimum of 1 month and a maximum of 6 months duration were taken as the study group. In addition to the demographic (age, sex) information of the cases, ultrasound results and pathologic diagnoses were obtained through the hospital information system. The localization of the enlarged lymph nodes, the longest diameter at ultrasound and the length of the CNB tissue of all these cases were recorded.

$\mathrm{CNB}$ and excisional biopsy sections were obtained from formalin fixed-paraffin embedded tissues, stained with hematoxylin-eosin and examined under the light microscope. Immunohistochemical tests required for diagnosis were performed with standard protocols. Lymphoma subtyping was performed according to the WHO classification (13). The final diagnosis of CNB and excision of the same lymph nodes were compared.

The Chi-square McNemar test was used for statistical analysis. Sensitivity, specificity, negative predictive value (NPV), positive predictive value (PPV) and true accuracy rates were calculated.

\section{RESULTS}

Of these 60 cases, 37 were male and 23 were female. The mean age was 50.8 (19-74). 21 of the excised lymph nodes were cervical, 16 were axillary, 9 were inguinal, 5 were supraclavicular, 5 were intraabdominal, and 4 were submandibular. The CNB and excision biopsy diagnoses of these 60 cases were reviewed and compared. When CNB diagnoses were examined, 8 (13.3\%) were found to be non-diagnostic, 11(18.3\%) were benign and the remaining $41(68.3 \%)$ received various lymphoma diagnoses (Figure 1A-C). The distribution of the CNB diagnoses and the final diagnosis of excisional biopsy is shown in Table I. The excisional biopsy diagnosis of 8 inadequate CNB cases were found as follows: 3 benign (37.5\%), $2 \mathrm{HL}(25 \%), 1 \mathrm{~T}$ cell / histiocyte-rich large B-cell lymphoma (THRLBCL) (12.5\%), 1 diffuse large B-cell lymphoma (DLBCL) (12.5\%) and 1 mantle cell lymphoma (MCL) (12.5\%). As for the excisional biopsy diagnosis of 11 cases who has received a benign diagnosis in CNBs, 4 were found to be benign $(36.3 \%)$, while in $7(63.7 \%)$ the diagnosis was changed to a malignant lymphoma (5 HL, 1 DLBCL, 1 Follicular lymphoma-FL). Among the 11 cases with a B cell lymphoma suspicion, $9(81.8 \%)$ of them were diagnosed as DLBCL
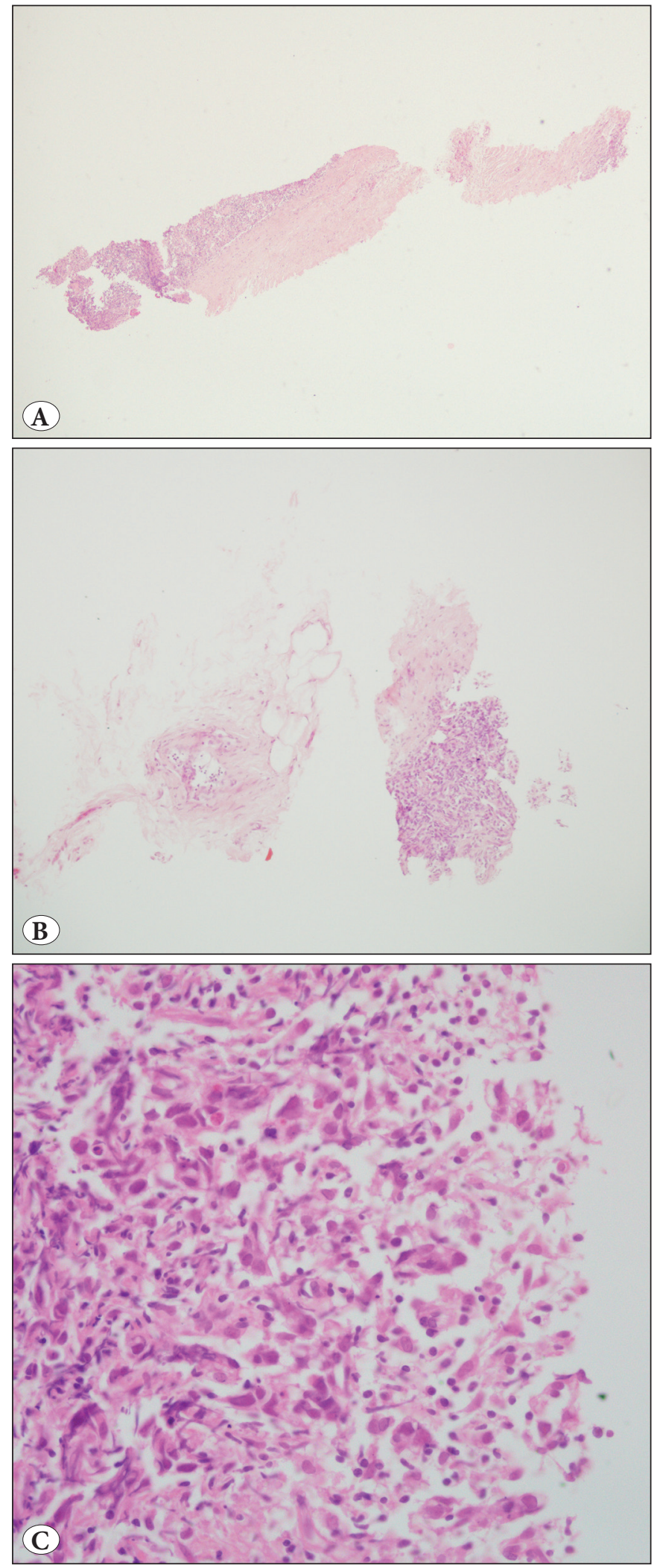

Figure 1: A) Small amount of lymphoid tissue and surrounding soft tissue (H\&E; x40). B) Lymphoid tissue showing crush artefact around adipose tissue (H\&E; x100). C) Lymphoid tissue showing significant crush artifact (H\&E; $\mathrm{x} 400)$. 
Table I: Distribution and comparison of CNB and excisional biopsy diagnoses

\begin{tabular}{lcccccccc}
\hline \multirow{2}{*}{$\begin{array}{l}\text { Cutting- needle } \\
\text { biopsy (CNB) }\end{array}$} & \multicolumn{7}{c}{ Excisional biopsy diagnosis } & \multirow{2}{*}{ Total } \\
\cline { 2 - 8 } & Benign-reactive & HL & DLBCL & FL & MCL & THRLBCL & CLL & \\
\hline Non-diagnostic & $3(37.5 \%)$ & $2(25.5 \%)$ & $1(12.5 \%)$ & $0(0 \%)$ & $1(12.5 \%)$ & $1(12.5 \%)$ & $0(0 \%)$ & $8(100 \%)$ \\
\hline Benign-reactive & $4(36.4 \%)$ & $5(45 \%)$ & $1(9.1 \%)$ & $1(9.1 \%)$ & $0(0 \%)$ & $0(0 \%)$ & $0(0 \%)$ & $11(100 \%)$ \\
\hline Hodgkin & $0(0 \%)$ & $12(100 \%)$ & $0(0 \%)$ & $0(0 \%)$ & $0(0 \%)$ & $0(0 \%)$ & $0(0 \%)$ & $12(100 \%)$ \\
\hline DLBCL & $0(0 \%)$ & $0(0 \%)$ & $6(100 \%)$ & $0(0 \%)$ & $0(0 \%)$ & $0(0 \%)$ & $0(0 \%)$ & $6(100 \%)$ \\
\hline MCL & $0(0 \%)$ & $0(0 \%)$ & $0(0 \%)$ & $0(0 \%)$ & $2(100 \%)$ & $0(0 \%)$ & $0(0 \%)$ & $2(100 \%)$ \\
CLL & $0(0 \%)$ & $0(0 \%)$ & $0(0 \%)$ & $0(0 \%)$ & $0(0 \%)$ & $0(0 \%)$ & $1(100 \%)$ & $1(100 \%)$ \\
\hline B cell. Lym suspicion & $0(0 \%)$ & $0(0 \%)$ & $9(81.8 \%)$ & $0(0 \%)$ & $2(18.2)$ & $0(0 \%)$ & $0(0 \%)$ & $11(100 \%)$ \\
\hline HL Suspicion & $0(0 \%)$ & $9(100 \%)$ & $0(0 \%)$ & $0(0 \%)$ & $0(0 \%)$ & $0(0 \%)$ & $0(0 \%)$ & $9(100 \%)$ \\
\hline Total & $7(11.7 \%)$ & $28(46.7 \%)$ & $17(28.3)$ & $1(1.7 \%)$ & $5(8.3 \%)$ & $1(1.7 \%)$ & $1(1.7 \%)$ & $60(100 \%)$ \\
\hline
\end{tabular}

HL: Hodgkin lymphoma (HL), DLBCL: Diffuse large B-cell lymphoma, FL: Follicular lymphoma, MCL: Mantle cell lymphoma, CLL: Chronic lymphocytic leukaemia/small lymphocytic lymphoma, THRLBCL: T cell/histiocyte-rich large B-cell lymphoma

and $2(18.2 \%)$ as MCL. 12 cases with a HL diagnosis and 9 cases with HL suspicion with CNBs were all diagnosed as HL with excisional biopsies (Figure 2A-D). There was no difference between excisional biopsy and CNB diagnoses in other lymphoma types.

Excluding 8 non-diagnostic CNBs from evaluation, CNB and excisional biopsy diagnoses were compared. As shown in Table II, among the 11 cases diagnosed as benign with $\mathrm{CNB}, 4$ of them were diagnosed as benign while 7 were diagnosed as malignant in excisional biopsy. All the 41 cases of malignant CNB diagnoses also had a malignant diagnosis with excisional biopsies, leading to 41 true positive, 4 true negative, 7 false negative and 0 false positive cases among the $\mathrm{CNB}$ diagnoses. According to these data, sensitivity of CNB was calculated as $90 \%$, while specificity, positive predictive value (PPV), negative predictive value (NPV) and diagnostic accuracy (DV) were found 100\%, $100 \%, 0 \%$ and $86.5 \%$, respectively.

Applying the Chi-square McNemar test, a linear, moderate power correlation was found between $\mathrm{CNB}$ and excision biopsy diagnoses $(\mathrm{Rho}=0.534 ; \mathrm{p}<0.001)$.

The mean lymph node diameter of the 8 benign cases was $26.1 \mathrm{~cm}$, while it was $35.6 \mathrm{~cm}$ in the 52 malignant cases, showing no statistically significant difference between the benign and malignant groups ( $\mathrm{p}>0.05)$.

We also evaluated whether there was a correlation between the CNB lengths of these 60 cases and the final excisional biopsy diagnoses. The biopsy core length median value was analyzed according to the diagnosis consistency of the cases. Inconsistently determined median core length was $1.25 \mathrm{~cm}$, while consistently determined median core length was 1.5 $\mathrm{cm}$. There was no difference in core length median value
Table II: Comparison of cutting-needle biopsy (CNB) and excisional biopsy diagnoses of lymph nodes

\begin{tabular}{lccc}
\hline CNB & \multicolumn{2}{c}{ Excisional biopsy diagnosis } & \multirow{2}{*}{ Total } \\
\cline { 2 - 3 } diagnosis & Benign & Malignant & \\
\hline Benign & $4(36.4 \%)$ & $7(63.6 \%)$ & $11(100 \%)$ \\
\hline Malignant & $0(0 \%)$ & $41(100 \%)$ & $41(100 \%)$ \\
\hline Total & $4(7.7 \%)$ & $48(92.3 \%)$ & $52(100 \%)$ \\
\hline
\end{tabular}

according to diagnosis consistency $(\mathrm{Z}=1.192 ; \mathrm{p}=0.233)$. Finally, ROC analysis was performed to see if a cut-off point for core length exists for diagnostic accuracy, but significant results were not obtained (AUC $=0.609 ; \mathrm{p}=0.244)$.

\section{DISCUSSION}

A CNB procedure performed under ultrasound or CT guidance is a successful diagnostic method performed on a wide variety of organs $(3,14)$. The CNB procedure applied to the lymph nodes has excellent results with a low risk of damage to surrounding tissues and minor complications (11, $14,15)$. Instead of excision of deeply-located lymph nodes, especially in the difficult to reach mediastinum or abdomen, the $\mathrm{CNB}$ procedure reduces the patient's morbidity and hospital stay and provides considerable advantages $(15,16)$. Recent developments in histopathological and especially immunohistochemical examination have changed the CNB approach and made it possible to make a diagnosis even in small tissue specimens $(8,11,15)$. CNB allows the enlarging lymph nodes to be distinguished not just as benign or malignant, but can even lead to diagnoses of the HL and NHL subtypes (12). Subtyping of some lymphomas can be very difficult with CNB but subtyping in excisional biopsies may also be impossible (8). In the literature, different ratios for the sensitivity and specificity of image-guided biopsy 
have been reported. In a study by Demharter et al., $89 \%$ sensitivity and $97 \%$ specificity for malignant lymphomas were reported (15), while Pfeiffer and colleagues provided rates of $89.7 \%$ and $100 \%$, respectively, with a diagnostic accuracy rate of $93.3 \%$ (12). In our study, we found $90 \%$ sensitivity and $100 \%$ specificity of CNBs on enlarged lymph nodes. Our results were consistent with the literature.

Five of the 7 cases initially reported as benign/reactive and were diagnosed as HL in excisional biopsies specimens were re-evaluated, as well as the ones diagnosed as DLBCL and FL. The reason for the missed diagnosis of HL was found to be CNB being performed from fields where there were only a few atypical cells on a reactive background. The FL case had a heterogeneous developmental pattern and a benign diagnosis was given due to the presence of reactive lymphoid follicles in the CNB biopsy specimen. As for the DLBCL case, the histomorphologic appearance could not be clearly selected due to the significant crush artifact in the tissue and immunohistochemistry did not work properly.

Re-evaluation was also done for the 8 non-diagnostic cases. It was noticed that in four cases there were lymphoid cell-free fibroadipose tissue and in two cases, most of the
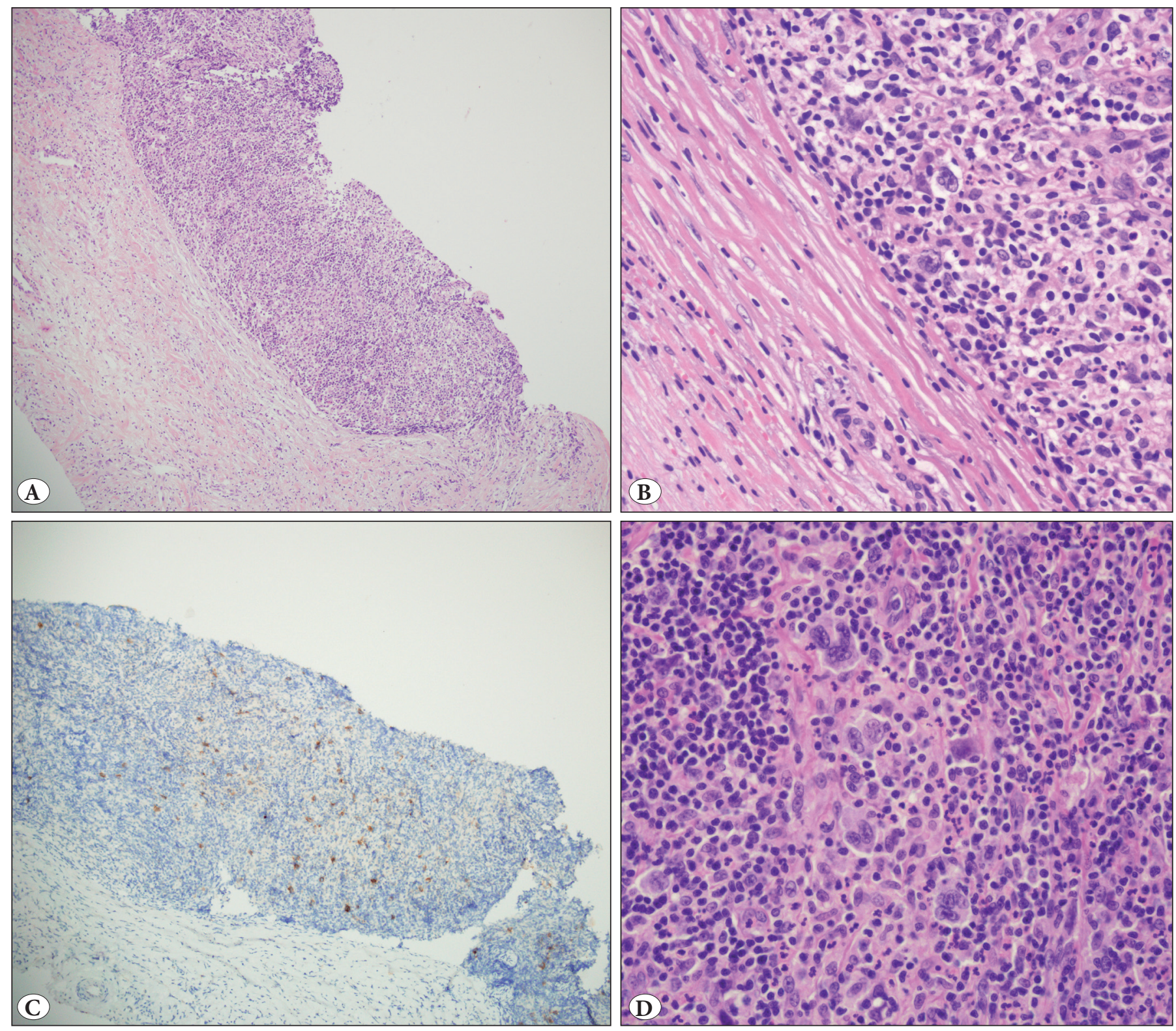

Figure 2: A,B) Numerous Hodgkin and Reed-Sternberg cells in reactive ground on CNB sections (H\&E; x40 and x400). C) CD30 positive Hodgkin's cells (CD30; x100). D) In the excisional biopsy of the same case, a large number of Hodgkin and Reed-Sternberg cells (H\&E; $\mathrm{x} 400)$. 
material consisted of fibroadipose tissue and very few lymphoid cells existed. In one case, there was adequate lymphoid tissue in the primary sections, whereas in the serial sections for immunohistochemical studies, lymphoid tissue disappeared. In the last one, a clear diagnosis could not be made due to the obvious degeneration at the edges of the tissue.

Pedersen et al. reported that the diameter of the lymph nodes with a malignant diagnosis was greater than benign ones and found a statistically significant difference (11). In our study, there was no statistically significant difference between the diameter of the lymph nodes and the malignant/ benign diagnosis. This may be due to the fact that clinicians and surgeons may decide on the excision of lymph nodes that have pathologic diameters and signs of malignancy on imaging tests.

Like the diameter of the lymph nodes, there was no statistically significant difference between the length of the $\mathrm{CNBs}$ and a correct diagnosis $(\mathrm{p}=0.898)$. It may be concluded that a smaller but well-preserved tissue piece obtained by $\mathrm{CNB}$ without crushing artifacts is more valuable than a bigger but improper sample in reflecting the pathology of lymph node.

This study is confined to CNB cases that later underwent excisional biopsy, although it is used as a diagnostic method in our hospital. This may be considered the weakness of the study and can be overcome by using larger series via patient follow-up programs.

In conclusion, $\mathrm{CNB}$ is an alternative to excisional biopsy, because it provides rapid and reliable diagnosis and subclassification of malign lymphomas, not only in peripheral lymph nodes but also especially in deeply located ones that are particularly difficult to excise. CNB is advantageous in terms of low morbidity and cost and can take the place of excisional biopsies in many cases. However, if clinical, laboratory, and radiological findings strongly suggest malignant lymphoma, we recommend using the excisional method in cases where there is no definite or negative $\mathrm{CNB}$ diagnosis.

\section{CONFLICT of INTEREST}

The authors declare no conflict of interest.

\section{REFERENCES}

1. Agid R, Sklair-Levy M, Bloom AI, Lieberman S, Polliack A, Ben-Yehuda D, Sherman Y, Libson E. CT-guided biopsy with cutting-edge needle for the diagnosis of malignant lymphoma: Experience of 267 biopsies. Clin Radiol. 2003;58:143-7.
2. Whelan JS, Reznek RH, Daniell SJ, Norton AJ, Lister TA, Rohatiner AZ. Computed tomography (CT) and ultrasound (US) guided core biopsy in the management of non-Hodgkin's lymphoma. Br J Cancer. 1991;63:460-2.

3. Demharter J, Neukirchen S, Wagner T, Schlimok G, Bohndorf K, Kirchhof K. Do ultrasound-guided core needle biopsies of lymph nodes allow for subclassification of malignant lymphomas? Rofo. 2007;179:396-400.

4. de Kerviler E, de Bazelaire C, Mounier N, Mathieu O, Brethon B, Briere J, Marolleau JP, Brice P, Gisselbrecht C, Frija J. Imageguided core-needle biopsy of peripheral lymph nodes allows the diagnosis of lymphomas. Eur Radiol. 2007;17:843-9.

5. Laffers W, Eggert K, Schildhaus HU, Bootz F, Gerstner AO. Histologic diagnoses in persistently swollen cervical lymph nodes. Head Neck. 2012;34:371-5.

6. Picardi M, Gennarelli N, Ciancia R, De Renzo A, Gargiulo G, Ciancia G, Sparano L, Zeppa P, Martinelli V, Pettinato G, Lobello R, Pane F, Rotoli B. Randomized comparison of power Doppler ultrasound-directed excisional biopsy with standard excisional biopsy for the characterization of lymphadenopathies in patients with suspected lymphoma. J Clin Oncol. 2004;22:3733-40.

7. Shaw JH, Rumball EM. Complications and local recurrence following lymphadenectomy. Br J Surg. 1990;7:760-4.

8. Sklair-Levy M, Amir G, Spectre G, Lebensart P, Applbaum Y, Agid R, Lieberman S, Ben-Yehuda D, Sherman Y, Libson E. Image-guided cutting-edge-needle biopsy of peripheral lymph nodes and superficial masses for the diagnosis of lymphoma. J Comput Assist Tomogr. 2005; 29:369-72.

9. de Kerviler E, Benet C, Briere J, de Bazelaire C. Image-guided needle biopsy for diagnosis and molecular biology in lymphomas. Best Pract Res Clin Haematol. 2012;25:29-39.

10. Rikabi A, Hussain S. Diagnostic usefulness of tru-cut biopsy in the diagnosis of breast lesions. Oman Med J. 2013;28:125-7.

11. Pedersen OM, Aarstad HJ, Lokeland T, Bostad L. Diagnostic yield of biopsies of cervical lymph nodes using a large (14-gauge) core biopsy needle. Apmis. 2013;121:1119-30.

12. Pfeiffer J, Kayser G, Ridder GJ. Sonography-assisted cutting needle biopsy in the head and neck for the diagnosis of lymphoma: Can it replace lymph node extirpation? Laryngoscope. 2009;119:68995.

13. Swerdlow SH, Elias C, Harris N L, Jaffe ES, Pileri SA, Stein H, Thiele J, Vardiman J W. WHO Classification of Tumours of Haematopoietic and Lymphoid Tissues. 4 th ed. Lyon:IARC;2008.

14. Screaton NJ, Berman LH, Grant JW. Head and neck lymphadenopathy: Evaluation with US-guided cutting-needle biopsy. Radiology. 2002;224:75-81.

15. Demharter J, Muller P, Wagner T, Schlimok G, Haude K, Bohndorf K. Percutaneous core-needle biopsy of enlarged lymph nodes in the diagnosis and subclassification of malignant lymphomas. Eur Radiol. 2001;11:276-83.

16. de Kerviler E, Guermazi A, Zagdanski AM, Meignin V, Gossot D, Oksenhendler E, Mariette X, Brice P, Frija J. Image-guided coreneedle biopsy in patients with suspected or recurrent lymphomas. Cancer. 2000;89:647-52. 